\title{
SMART: a Simple Model to Assess Range Technology
}

RICHARD H. HART

\section{Abstract}

A model, more detailed than a set of stocking rate response curves but less detailed than large process models such as SPUR, was needed to evaluate the short-term effect of grazing management practices on range herbage growth and livestock production. SMART (Simple Model to Assess Range Technology) simulates the effects of stocking rate and rotation on herbage production and steer performance. Herbage growth rate is a quadratic function of herbage biomass and is adjusted for seasonal differences. Herbage intake increases with herbage biomass and digestibility and animal weight. Animal gain increases logarithmically with digeatible dry matter intake and decreases with animal weight. Output of these simulations confirms that early removal of steers from pasture in autumn will increase net returns, and that short-duration rotation grazing will produce little increase in gains or returns over those achieved under season-long grazing. Development of the SMART model revealed deficiencies in our understanding of the factors controlling herbage intake.

Key Words: herbage production, modelling, grazing systems, steer performance

Many process models of grazing ecosystems have been developed in the past 20 years (Goodall 1979). SPUR (Simulation of Production and Utilization of Rangelands; Wight 1987b) and other models of this sort tend to be mathematically complex and extremely detailed. Such detail often is not needed, wanted, or understood by stockmen or by researchers conducting grazing studies.

A simpler approach to modeling was suggested by Noy-Meir (1978), based on his earlier work with predator-prey graphs (NoyMeir 1975). He plotted herbage growth and consumption as functions of herbage biomass, and drew conclusions about the productivity and stability of grazing systems as influenced by the balance between the two processes. His models are concerned with longterm equilibria in which animal numbers are controlled by forage availability, and have several deficiencies when applied to a single grazing season on rangeland. The models assume that herbage growth rate is a constant quadratic function of herbage biomass throughout the season, with growth stopping abruptly on a fixed date. They also assume that consumption of green biomass by each animal is a constant function of total green biomass throughout the season, without regard to changes in digestibility, animal weight, or stage of production (i.e., pregnancy or lactation). In the original model (Noy-Meir 1975), herbage consumption was a Michaelis or logarithmic function of biomass; the later version assumed a discontinuous or ramp function (Noy-Meir 1978). Stable equilibrium points were proposed when consumption and growth were equal and when a decrease in herbage biomass caused an increase in growth.

Under some conditions, a sudden collapse in gains was predicted, with gain per unit area falling abruptly from near maximum to less than zero with a very small increase in stocking rate (SR). The data of Bement (1974) and Hart et al. (1988b), in which SR greatly exceeded that at maximum gain per unit area and in one

\footnotetext{
Author is range scientist, USDA-ARS, High Plains Grasslands Research Station, Cheyenne, Wyoming 82009.

Manuscript accepted 5 December 1988.
}

case was so high that cattle lost weight, showed no such sudden decrease in gain. Experimental evidence indicates a "plateau" of constant gain per animal at grazing pressures below some critical level, and a linear decline in gain as grazing pressure increases past this level (Hart 1978). Any model must account for these responses.

\section{Assumptions, Development and Validation of SMART}

SMART assumes that herbage growth rate is a quadratic function of herbage biomass (both measured as dry matter), but that growth rate at any given level of biomass declines as the growing season advances, rather than holding constant. In some climates and ecosystems, growth rate increases in the fall and continues at a low rate through the winter; SMART could be modified accordingly for such ecosystems. Digestibility of diets also decreases as the season advances; again, this may not be true of all ecosystems. Intake of digestible dry matter (DDM) increases linearly as the standing crop of DDM increases, until maximum intake is achieved. The rate of increase becomes smaller as animal weight increases. Maximum intake of dry matter increases as animal weight and rumen capacity increase, but decreases as digestibility and the ease of meeting energy demand increase. Animal gain is a logarithmic function of animal weight times DDM intake, after an allowance for maintenance is deducted from intake; this is a simplification of the more complex function used by NRC-NAS (1984).

Parameters for the functions were calculated from published and unpublished data. The herbage growth function was fit to 1982 data of Test (1984); he measured herbage production and steer gains on blue grama-western wheatgrass range near Cheyenne, Wyoming. This function predicts net herbage biomass growth, or total growth minus losses from weathering, trampling, and rodent and insect grazers. A net loss in biomass in autumn is predicted and has been shown to occur. Dry matter digestibility of diet declines linearly during the season but at changing rates as the botanical composition of the diet changes (Hart et al. 1983).

DDM intake was fit to data of Zoby and Holmes (1983) from heavier cattle and from data of Test (1984) at the end of the grazing season, when nutrient availability and/or density limited intake. Test (1984) did not measure intake, but calculated intake from his data on standing crop inside and outside of exclosures which were moved every two weeks. Maximum intake was fit to Test's (1984) data in mid-season and to Zoby and Holmes' (1983) data from lighter cattle; it was assumed that intake was not limited by DDM availability in either case. Fit of data to a discontinuous function with a ceiling on intake was much superior to fit to Michaelis, logarithmic, inverse, or other continuous functions. Daily intake calculated from the data of Allden and Whittaker (1970) relating grazing time and rate of intake to herbage availability demonstrated this response. The upper limit is fixed by rumen capacity and rate of passage. Difference equations and symbols used are listed in Table 1.

The single-paddock version of SMART requires 46 lines when coded in BASIC 3.11; the multi-paddock version requires 56 lines. Coding may be obtained from the author.

SMART requires input of initial values of $S R$, animal weight, and herbage biomass; the day grazing begins and ends; and a growth factor (the value .000001 in the first equation of Table 1) by 
Table 1. Equations and symbols used in SMART.

\begin{tabular}{|c|}
\hline Equations \\
\hline $\begin{array}{l}G=\left(72000 \mathrm{~V}-36 \mathrm{~V}^{2}-263 \mathrm{VT}+0.128 \mathrm{~V}^{2} \mathrm{~T}\right) .000001 \\
D_{(T<188)}=108.1-0.25 \mathrm{~T} \\
D_{(\mathrm{T}>187,<218)}=92.75-0.167 \mathrm{~T} \\
D_{(T>217)}=110.85-0.25 \mathrm{~T} \\
I_{D D M}=(0.029-0.000039 \mathrm{~W})(\mathrm{DV} / 100) \\
I_{D M \max }=0.051 \mathrm{~W}-0.00037 \mathrm{DW} \\
L=(3.12-0.45 \text { in W })\left(I_{D D M}-0.042 \mathrm{~W}^{.75}\right)\end{array}$ \\
\hline Symbols \\
\hline $\begin{array}{l}\text { G = Herbage growth rate, } \mathrm{kg} \text { dry matter } / \mathrm{ha} / \text { day } \\
\mathrm{V}=\text { Herbage standing crop, } \mathrm{kg} \text { dry matter } / \mathrm{ha} \\
\mathrm{T}=\text { Day of year (Julian date) } \\
\mathrm{D}=\text { Dry matter digestibility, } \% \\
\mathrm{I}_{\mathrm{DDM}}=\text { Intake of digestible dry matter, } \mathrm{kg} / \mathrm{animal} / \mathrm{day} \\
\mathrm{I}_{\mathrm{DM} \text { max }}=\text { Maximum intake of dry matter, } \mathrm{kg} / \mathrm{animal} / \mathrm{day} \\
\mathrm{L}=\text { Gain per animal, } \mathrm{kg} / \text { day } \\
\text { W = Animal weight, } \mathrm{kg}\end{array}$ \\
\hline
\end{tabular}

which growth rate is adjusted to achieve the desired value for peak standing crop in an exclosure. SMART then operates on a daily time step. First, herbage growth is calculated for grazed and ungrazed stands (the latter simulates the exclosure) and added to the biomass of each, and dry matter digestibility is calculated. Next, digestible, total and maximum dry matter intake per animal are calculated; if the calculated dry matter intake exceeds maximum intake, total and digestible dry matter intake are reduced accordingly. Then gain per animal is calculated and animal weight and gain per hectare are incremented. Finally, dry matter intake per hectare is calculated from intake per animal and stocking rate, and deducted from herbage biomass. The effect of herbage biomass on herbage growth and intake as digestibility decreases and animal weight increases are shown in Figure 1.

As now coded, SMART prints at daily or longer pre-selected intervals the Julian date, standing crop and growth rate in each paddock, the paddock being grazed, dry matter digestibility, dry matter intake per steer, daily gain, and steer weight. At the end of the grazing season it prints peak exclosure standing crop and total dry matter consumption from each paddock, average daily gain

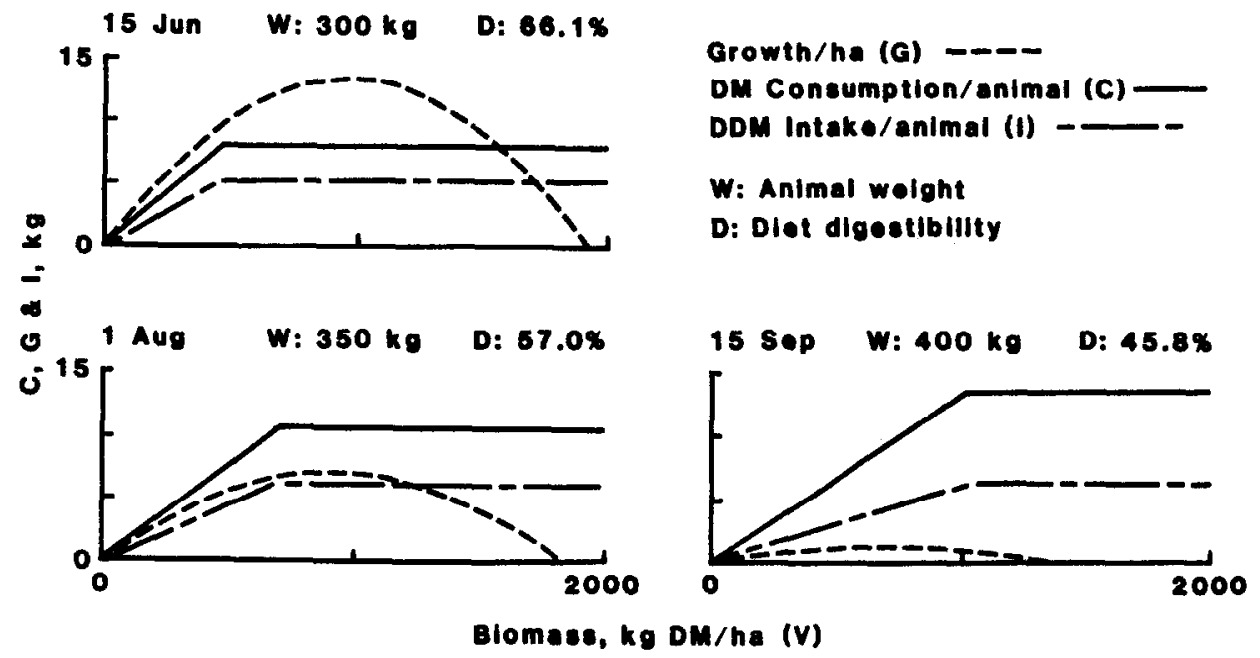

and gain per ha for the season, and the SR and growth factor originally specified.

SMART was validated using 1983 data from Test (1984) and 1984 data from Hart (1988a) collected at Cheyenne. Biomass predicted by the model was greater than that in the field in 1983 and less in 1984 (Fig. 2) but by only a small margin, and seasonal
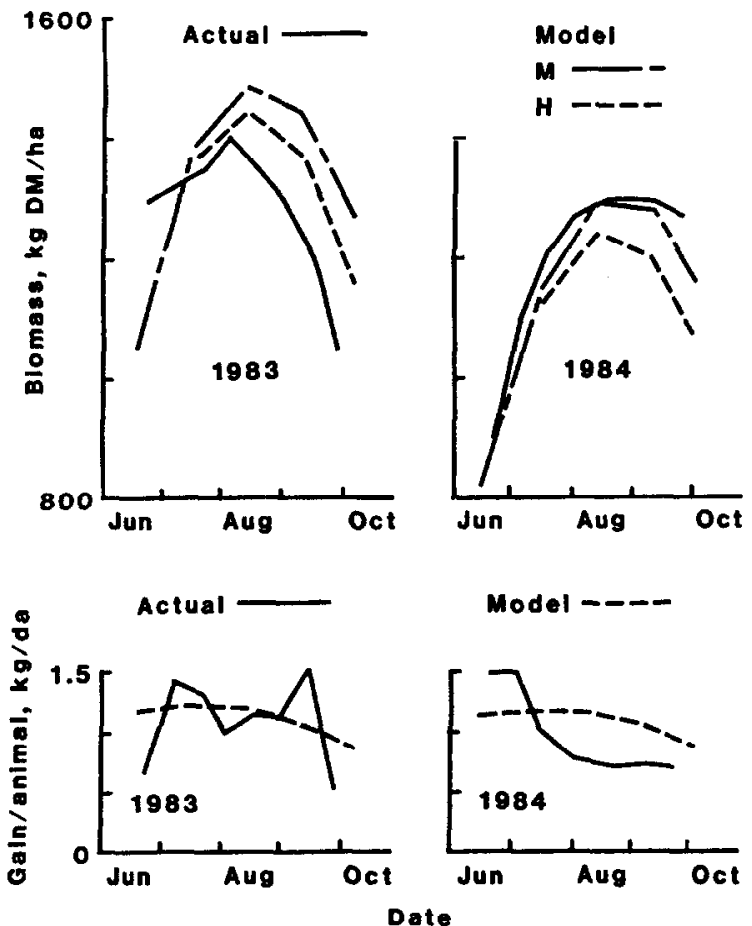

Fig. 2. Validation of herbage biomass and animal gain simulations of SMART; $M=$ moderate stocking, $H=$ heavy stocking.

patterns were the same in the model and in the field. However, as indicated by the name, SMART is designed not to simulate forage growth in response to environment, but to evaluate the impact of grazing technology on animal intake and gains, and the feedback of intake to forage growth. SMART predicted actual gains very closely but without the fluctuations between weigh dates observed when animals are weighed frequently.

\section{Dlot digestiblity}

Fig. 1. Response of herbage growth to herbage biomass and date, and of herbage intake to herbage biomass and digestibility and animal weight; SMART simulations. 


\section{Applications of SMART to Management and Research}

SMART was run over a range of SR for grazing seasons beginning 1 or 15 June and ending 15 September or 15 October and assuming forage production of $1,326 \mathrm{~kg} / \mathrm{ha}$. Over each season, the response of gain per animal followed the standard SR curves (Fig. 3), indicating the model is a useful approximation of reality. No large drop in gains was predicted at high SR. This conforms to reality on range, where grazing seldom begins until a reserve of forage has been produced, and forage intake by grazing animals declines gradually, not abruptly, as forage supply decreases.

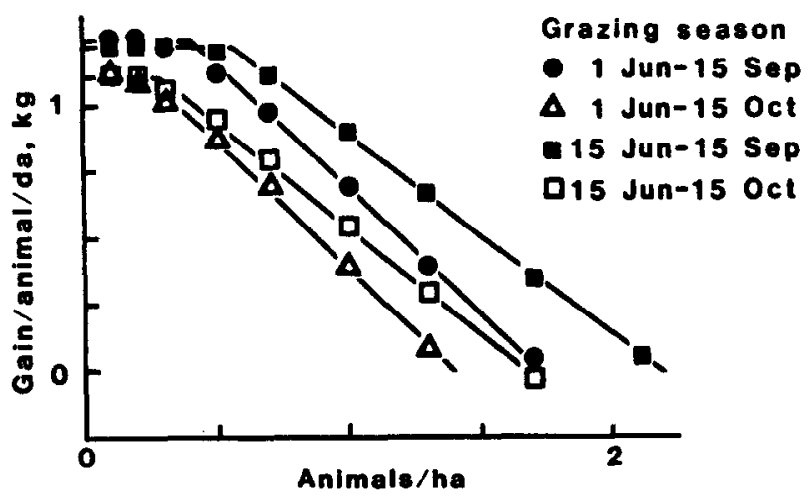

Fig. 3. Effect of stocking rate on gain per animal over 4 grazing schedules: SMART simulations.

Stocking rate response curves can be used by a livestock producer to make simple pencil-and-paper calculations of the most profitable SR under his range and economic conditions (Hart 1978 and Hart et al. 1988a). Equations for the stocking rate-gain curves of Figure 3 are given in Table 2, with SR converted from head/ha

Table 2. Average daily galn (ADG) above critical graning pressure, optmum stocking, rate, and ADG and net return at optimum stocking rate for four grazing seasons (SMART simulation).

\begin{tabular}{clccc}
\hline \hline & ADG & Optimum & ADG, optimum H- & Return/ \\
Grazing season & $(\mathbf{H}=$ steer da/ha) & H & kg & ha \\
\hline 1 Jun - 15 Sep & $1.61-0.00870 \mathrm{H}$ & 66.8 & 1.03 & $\$ 61.75$ \\
1 Jun - 15 Oct & $1.33-0.00693 \mathrm{H}$ & 63.8 & 0.89 & 44.79 \\
15 Jun - 15 Sep & $1.65-0.00830 \mathrm{H}$ & 72.2 & 1.05 & 68.80 \\
15 Jun - 15 Oct & $1.33-0.00648 \mathrm{H}$ & 67.8 & 0.89 & 47.34 \\
\hline
\end{tabular}

to steer days/ ha. The optimum or most profitable SR is calculated from the equation

$$
\mathrm{H}=(\mathrm{Pa}-\mathrm{C}) /(2 \mathrm{~Pb}) \text {, }
$$

in which $\mathrm{H}=$ optimum $\mathrm{SR}, \mathrm{P}=$ selling price in dollars per $\mathrm{kg}, \mathrm{C}=$ carrying cost per head per day, and values of $a$ and $b$ are taken from the equations in Table 2. These equations also are used to calculate ADG at the optimum SR. Net return/ha to land, labor and management or $\mathbf{R}$ is calculated by the equation

$$
\mathrm{R}=(\mathbf{P a}-\mathbf{C}) \mathbf{H}-\mathbf{P b H}^{2} \text {. }
$$

Average selling price in September and October of 1987 was $\$ 1.59 / \mathrm{kg}$ and carrying costs in 1987 were estimated at \$0.71/ head/day (Hart et al. 1988a). Gains and returns estimated from SMART simulations were much higher when steers were removed from pasture 15 September rather than waiting until 15 October. As forage biomass and quality declined in late September and early October, intake and steer gains also declined while carrying costs remained the same, reducing net returns.
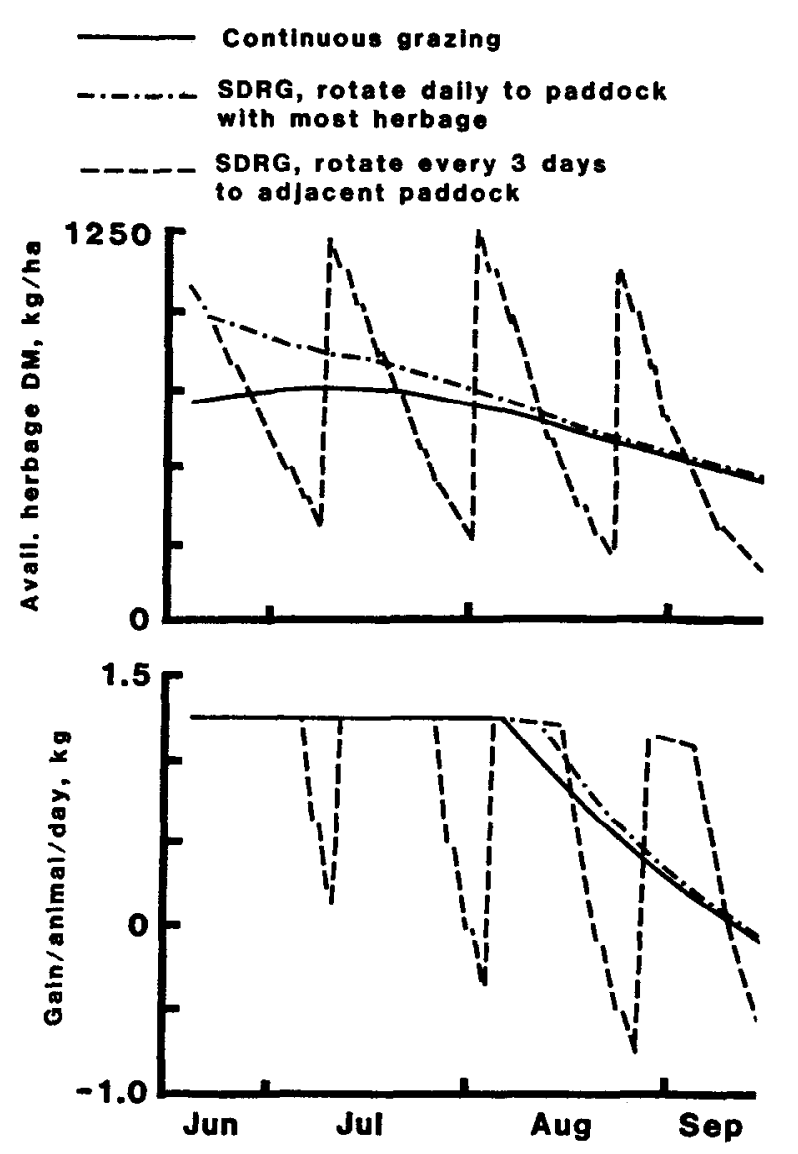

Fig. 4. Herbage availability and animal gain under continuous grazing and 8-paddock short-duration rotational grazing ( $S D R G$ ) with cattle moved daily to the paddock with greatest herbage standing crop or every 3 days to the adjacent paddock; SMART simulations.

SMART provides information about the operation of rotation grazing systems. This model was used to simulate rotation patterns in an 8-paddock rotational grazing system, in which growth rate in the paddocks ranged from one-third less than the mean growth rate to one-third more. When steers were rotated daily to the paddock with the greatest herbage biomass, simulated gain per steer for the season was $4 \%$ greater than that simulated under continuous season-long grazing. But when steers were rotated through the paddocks in order every 3 days, without regard to herbage biomass, available forage and animal gain varied greatly from paddock to paddock and day to day, and total gain was $20 \%$ less than under season-long grazing (Fig. 4). These responses are confirmed by Hart et al. (1988a), who reported that gains under 8-paddock short duration rotation grazing were not significantly different from gains under season-long grazing when rotation was based on herbage biomass and assumed growth rate, but were $16 \%$ less when animals were rotated according to a set schedule.

The most significant effect of chemical and mechanical treatments on range is an increase in forage production. SMART can simulate this increase and estimate its impact on livestock gains, providing a basis for economic evaluation of proposed treatments.

The herbage growth and digestibility equations of SMART may be modified to match the average response of range and pasture types other than blue grama-western wheatgrass range. Most of the necessary data probably has been published, or languishes in researchers' files awaiting application. Temperature, solar radiation, and precipitation parameters may be added as driving variables for herbage growth and digestibility. The ERHYM model provides an example (Wight 1987a). No attempt was made to 
simulate growth of individual plant species. Caughley (1982) has stated that the dynamics of a system made up of several plant species can often be summarized by a one-species model. However, a multi-species model is necessary if succession is to be simulated, or if shifts of plant species in the diet cause significant changes in diet quality.

The intake and gain equations may be modified to fit other species and classes of livestock, on other forage types. For example, intake on improved pastures in humid areas is much less than that on rangeland with the same standing crop of digestible biomass (Hodgson and Wilkinson 1968, Jamieson and Hodgson 1979).

The SR response curves developed from SMART indicate appropriate $S R$ to include in grazing trials. There is little value to grazing trials in which all SR are below the critical SR, and all gains are equal. As a result of our work with this model, we increased SR on a grazing systems and stocking rate study by $25 \%$ (Hart et al. 1988a).

The curves also provide a format for quantifying and reporting results of grazing trials. Too many publications conclude, after 10 to $\mathbf{4 0}$ years of research, only that "moderate" stocking produced more gain per hectare than "heavy" stocking; a very small return of information for an enormous investment in land, time, and money. Response curves developed from such data sets would be valuable guides to stockmen operating on many types of range and pasture.

Finally, development of models such as SMART stimulate the formulation of researchable hypotheses and the identification of data needed to enlarge our understanding of the operation of plant-animal systems. Our search for data to paramaterize and validate SMART revealed the shortage of range data relating herbage intake to standing crop of forage; digestibility or other measure of forage quality; and animal species, class, weight, and condition. Estimating intake of grazing animals is always difficult, but especially under range conditions where a large area per animal is needed and difficulties in handling animals are increased proportionately.

\section{Literature Cited}

Allden, W.G., and I.A. McD. Whittaker. 1970. The determinants of herbage intake by grazing sheep: the interrelationship of factors ininfluencing herbage intake and availability. Aust. J. Agr. Res. 21:755-766.
Bement, R.E. 1974. Strategies used in managing blue-grama range on the Central Great Plains. p. 108-120 In: Kreitlow, K.W., and R.H. Hart (eds.) Plant morphogenesis as the basis for scientific management of range resources. USDA Misc. Pub. 1271.

Caughley, G. 1982. Vegetation complexity and the dynamics of modelled grazing systems. Oecol. 54:309-312.

Goodall, D.W.1979. The modeling of arid ecosystem dynamics. p. 385-409. In: Goodall, D.W., and R.A. Perry (eds.) Arid-land ecosystems: structure, functioning and management, vol. 2. Cambridge Univ. Press, Cambridge.

Hart, R.H. 1978. Stocking rate theory and its application to grazing on rangelands. p. 547-550 In: Hyder, D.N. (ed.) Proc. 1st Internat. Range. Cong. Soc. Range Manage., Denver, Colo.

Hart, R.H., O.M. Abdalla, D.H. Clark, M.B. Marshall, M.H. Hamid, J.A. Hager, and J.W. Waggoner, Jr. 1983. Quality of forage and cattle diets on the Wyoming High Plains. J. Range Manage. 36:46-54.

Hart, R.H., M.J. Samuel, P.S. Test, and M.A. Smith. 1988a. Cattle, vegetation and economic responses to grazing systems and grazing pressure. J. Range Manage. 41:282-286.

Hart, R.H., J.W. Waggoner, Jr., T.G. Dunn, C.C. Kaltenbach, and L.D. Adams. 1988b. Optimal stocking rate for cow-calf enterprises on native range and complementary improved pastures. J. Range Manage. 41:435-441.

Hodgson, J., and J.M. Wilkerson. 1968. The influence of the quantity of herbage offered and its digestibility on the amount eaten by grazing cattle. J. Brit. Grassl. Soc. 23:75-81.

Jamieson, W.S., and J. Hodgson. 1979. The effects of variation in sward characteristics upon the ingestive behavior and herbage intake of calves and lambs under a continuous stocking management. Grass \& Forage Sci. 34:273-282.

Noy-Meir, I. 1975. Stability of grazing systems: an application of predatorprey graphs. J. Ecol. 63:459-481.

Noy-Meir, I. 1978. Grazing and production in seasonal pastures: analysis of a simple model. J. Appl. Ecol. 15:809-820.

NRC-NAS. 1984. Nutrient requirements of beef cattle, 6th rev. ed. Nat. Acad. Press, Washington, DC.

Test, P.S. 1984. Vegetation and livestock response to three grazing systems - continuous, rotationally deferred and short-duration rotation. Ph.D. Diss., Univ. Wyoming, Laramie. Diss. Abstr. 8508879.

Wight, J.R. 1987a. ERHYM-II: Model description and user guide for the BASIC version. USDA-ARS Publ. ARS-59.

Wight, J.R. (project coord.) 1987b. SPUR-Simulation of Production and Utilization of Rangelands: documentation and user guide. USDA, ARS Publ. ARS-63.

Zoby, J.L.F., and W. Holmes. 1983. The influence of size of animal and stocking rate on the herbage intake and grazing behaviour of cattle. $J$. Agr. Sci. 100:139-148. 